Book review

\section{To boldly lead}

Leadership in Health Care

Jill Barr and Lesley Dowding

SAGE Publications Ltd; 2008

260 pp \$44.95 ISBN 978-1412920681

$\mathrm{T}$

he role of health care practitioners is to provide patients with advice and guidance about health and disease. This is what it means to be a teacher; this is what it means to be a leader.

For health practitioners however, leadership does not stop at the patient encounter. Leadership extends into office management, practice building and inter-professional interaction; into teambased management and synergistic outcomes. Leadership extends into the academic and collegial atmosphere creating opportunities for mentorship, professional advancement and continuing education. It promotes research, produces guidelines, and demands consistency of care. In short, leadership prevents a stagnant profession.

Throughout history, the health professions have exhibited leadership that all practitioners should emulate. The key to great leadership is complete understanding and management of one's strengths, weaknesses, management style and preferences. One must know thyself, before truly understanding others.

This is the journey that Jill Barr and Lesley Dowding take readers on in Leadership in Health Care. While carefully dissecting all the boundaries of leadership and team-based management, the authors systematically present a skill base that most mistake as a natural gift. The reader receives a complete overview of how to apply leadership at the individual, team and organizational levels directly to a health care setting.

The most constructive of the 3 organized parts is the one covering the individual. Here, the authors guide the reader in discovering their own leadership style, while analyzing their strengths and weaknesses. This is achieved by challenging the reader to probe his or her own personality via multiple models.

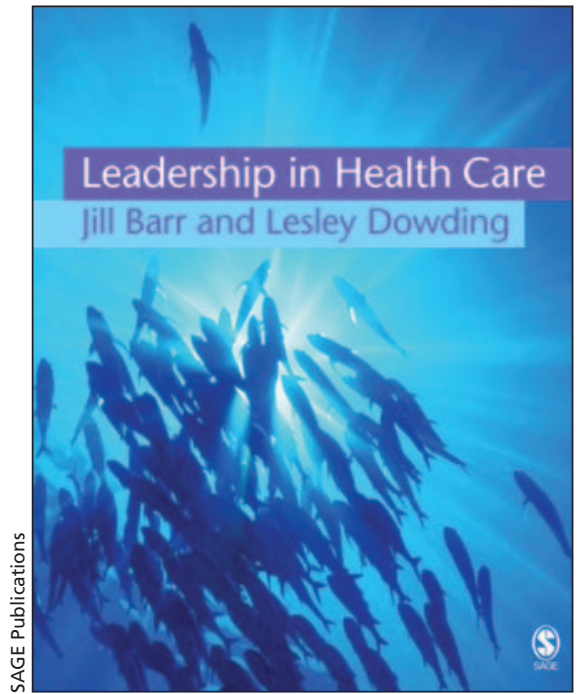

This allows one to anatomize one's approach in the leadership role and reflect on the leaders in one's own life.

A major strength of the text is the prevailing theme of personal reflection. Information is frequently offered in contextualized questions, which allow the reader to immediately use and solidify what they have learned. In addition, each chapter offers introductory syllabi, learning objectives and keypoint summaries.

Together, the authors have generated an enlightening text that can be enjoyably studied, rather than merely read, and can truly enhance one's professional attitude and approach. In this way, one may experience improvement in professional outcomes and satisfaction.

Barr and Dowding have generated a phenomenal review that will help any health professional clearly understand their roles as both leader and follower, while generating greater team organizational skills. Whether read by students, clinicians, managers or academics, this book will help improve all roles within health care.

\section{Robert Rodine BSc DC}

Graduate student

Canadian Memorial Chiropractic

College

Toronto, Ont.

\section{Poem}

\section{To his violin}

I found you, abandoned in the attic of my boyhood home, your broken bridge, rusting strings a testimony to disregard.

When had you last sung?

In what year did he last hold you in his loving hands?

Can you sing me a song of my lost father, of the times you had together the long dead maestro,

you, his prima donna. When did he last place you in your case, where you have waited

in aging velvet until gently lifted from that grave resting place, and I stroked your strings.

If I were to raise your frayed bow touch so lightly those strings, would you whisper why he lost interest

left you longing in your case? What was his new love that led to this estrangement? What ruled him,

that nothing else mattered his music, his family?

Sing me a song Of my lost father,

of the times you had together. Tell me of his passion. Whisper his secrets that I may understand.

\section{Richard Bronson MD}

Professor, obstetrics, gynecology and pathology

Stony Brook University Stony Brook, New York, USA 